\title{
Stabilisasi Tanah Lempung Ekspansif Menggunakan Kapur Tohor
}

\author{
Muhadi Aryanto, Suhendra*, Kiki Rizky Amalia \\ Teknik Sipil Universitas Batanghari Jambi \\ *Correspondence email: suhendra_domas@yahoo.com
}

\begin{abstract}
Abstrak. Tanah merupakan elemen penting dari dari sebuah struktur bawah sebuah konstruksi, sehingga tanah harus mempunyai daya dukung yang baik. Namun pada kenyataannya di lapangan banyak ditemukan tanah yang memiliki daya dukung yang sangat rendah, sehingga perlu untuk dilakukan stabilisasi tanah dengan kapur tohor. Penelitian ini bertujuan untuk mendapatkan nilai mendapatkan persentase yang efektif dalam penambahan kapur tohor, dan pengaruh penambahan kapur terhadap perubahan sifat fisis tanah dari segi nilai CBR (California Bearing Ratio) terhadap lama waktu pemeraman. Penelitian ini dilakukan di Laboratorium Fakultas Teknik Universitas Batanghari Jambi. Dengan melakukan pengujian sifat - sifat fisis tanah dan daya dukung tanah CBR (California Bearing Ratio) dengan variasi penambahan kapur $0 \%, 6 \%$, 7 \%, dan $8 \%$ dengan lama pemeraman 0 hari, 3 hari, dan 24 hari. Pada pengujian ini dilakukan dengan dua cara yaitu sampel tanah diperam terlebih lalu direndam kemudian baru di uji. Dari hasil penelitian didapat nilai CBR (California Bearing Ratio) terbesar terjadi pada variasi penambahan kapur tohor yaitu $8 \%$ dengan lama waktu pemeraman 24 hari dengan nilai CBR sebesar 27,95\%. Hal ini disebabkan campuran tanah dengan kapur tersebut telah memadat, rongga antar partikel tanah juga padat, sehingga kekuatan pun meningkat. Dari hasil CBR (California Bearing Ratio) dapat terlihat bahwa penambahan kapur tohor pada tanah lempung ekspansif memberikan peningkatan pada nila CBR (California Bearing Ratio).
\end{abstract}

Kata Kunci: Stabilisasi Tanah Lempung Ekspansif Menggunakan Kapur Tohor

\section{PENDAHULUAN}

Tanah dasar (Sub Grade) adalah lapisan tanah paling bawah yang berfungsi sebagai tempat perletakkan lapis perkerasan dan mendukung konstruksi perkerasan jalan diatasnya. Tanah dasar (Sub Grade) dapat berupa tanah asli yang dipadatkan jika tanah aslinya baik, tanah urugan yang didatangkan dari tempat lain atau tanah yang distabilisasikan dengan kapur, semen dan lain lain. Ditinjau dari muka tanah asli, maka tanah dasar dibedakan menjadi, tanah dasar (tanah galian), tanah dasar (tanah urugan), dan tanah dasar (tanah asli). Kekuatan dan keawetan konstruksi perkerasan jalan sangat tergantung dari sifat - sifat dan daya dukung tanah dasar, pada umumnya persoalan yang menyangkut tanah dasar adalah perubahan benttuk tetap (Deformasi permanen) akibat beban lalu lintas, sifat mengembang dan menyusutnya tanah akibat perubahan kadar air, dan daya dukung tanah yang tidak merata akibat adanya perbedaan sifat - sifat tanah pada lokasi yang berdekatan atau akibat kesalahan pelaksanaan yang mengakibatkan kepadatan yang kurang baik.

Maksud dari penelitian Tugas Akhir ini adalah untuk mengetahui perubahan sifat - sifat mekanis dan fisik dari tanah lempung ekspansif akibat penambahan kapur tohor.

Tujuan penelitian ini adalah :

1. Mendapatkan nilai CBR desain tanah lempung ekspansif yang distabilisasi dengan kapur tohor $6 \%, 7 \%$, dan $8 \%$.

2. Mendapatkan perbandingan nilai CBR desain ( $95 \%$ MDD ) pada campuran $6 \%, 7 \%$, dan $8 \%$.

\section{Tinjauan Pustaka}

Tanah adalah material yang terdiri dari agregat (butiran) mineral-mineral padat yang tidak tersementasi (terikat secara kimia) satu sama lain dari bahan-bahan organik yang telah melapuk (yang berpartikel padat) disertai zat cair juga gas yang mengisi ruang-ruang kosong diantara partikel-partikel padat tersebut (Braja M. Das, 1995).

Tanah lempung merupakan partikel - partikel berukuran mikroskopik dan submikroskopik yang berasal dari pembusukan kimiawi unsur - unsur penyusun batuan, dan bersifat plastis dalam selang kadar air sedang sampai luas. Dalam keadaan kering sangat keras, dan tak mudah terkelupas hanya dengan jari tangan, selain itu, permeabilitas lampung sangat rendah (Terzaghi dan Peck, 1987).

Tanah ekspansif adalah tanah yang mengalami perubahan volume akibat perubahan kadar air dalam lapisan tanah. Biasanya tanah ekspansif mengandung mineral - mineral lempung seperti smektit dan montmorilonit yang mampu menyerap air. Ketika mineral tersebut menyerap air maka volume tanah akan meningkat. Semakin banyak air yang terserap, semakin bertambah volume tanah. Perubahan volume ini dapat merusak kekuatan struktur bangunan yang menempati tanah tersebut. Pondasi, lantai, dan dinding yang retak pada suatu bangunan merupakan ciri khas kerusakan yang disebabkan oleh tanah ekspansif (expansive soil).

\section{Karakteristik Tanah Lempung Ekspansif}


Tanah (soil) terdiri dari berbagai material, yang sebagian besar tidak mengembang pada saat lembab. Namun, ada beberapa mineral lempung yang bersifat mengembang (ekspansiffexpand). Sifat ekspansif ini disebabkan oleh proses basah dan pengeringan yang silih berganti dan merupakan hasil perubahan dalam sistem tanah yang menggangu keseimbangan tegangan - tegangan dalam (Braja M. Das. 1995)

Tabel 1. Menentukan Tanah Ekspansif.

\begin{tabular}{ccc}
\hline Tingkat Pengembangan & Batas Cair \% & Indeks Plastis \% \\
\hline Tinggi & $>60$ & $>35$ \\
Sedang & $50-60$ & $25-35$ \\
Rendah & $<50$ & $<25$ \\
\hline
\end{tabular}

Sumber ( SNI - $03-6795-2002)$

\section{Kapur Tohor}

Batu kapur atau gamping dalam Bahasa inggris disebut Limestone merupakan sebuah batuan sedimen yang terdiri dari mineral kalsit dan argonit yang merupakan dua varian berbeda, atau dikenal pula dengan nama kimia kalsium oksida $(\mathrm{CaO})$, kapur tohor adalah hasil pembakaran kapur mentah (kalsium karbonat atau $\mathrm{CaCO}_{3}$ ) pada suhu kurang lebih 90 derajat Celcius. Menurut SNI - 03 - 4147 - 1996 kapur dibagi menjadi 4 macam yaitu :

1. Kapur tipe I yaitu kapur yang mengandung kalsium hidrat tinggi dengan kadar magnesium oksida $(\mathrm{MgO})$ paling tinggi $4 \%$.

2. Kapur tipe II yaitu kapur magnesium atau dolomite yang mengandung magnesium oksida lebih dari $4 \%$ dan maksimum $36 \%$ berat.

3. Kapur tohor $(\mathrm{CaO})$ yaitu hasil pembakaran batu kapur pada suhu $\pm 90^{\circ} \mathrm{F}$ dengan komposisi sebagian besar kalsium karbonat $\left(\mathrm{CaCO}_{3}\right)$.

4. Kapur padam yaitu kapur dari hasil pemadaman kapur tohor dengan air, sehingga terbentuk $\mathrm{Ca}(\mathrm{OH})_{2}$.

Kapur merupakan salah satu mineral yang cukup efektif untuk proses stabilisasi tanah. Stabilisasi tanah dengan kapur sangat lazim digunakan dalam proyek - proyek konstruksi jalan mau pun bangunan dengan berbagai macam jenis tanah, mulai dari tanah lempung biasa sampai tanah lempung ekspansif. Kapur yang biasa digunakan dalam stabilisasi tanah adalah kapur hidup $\mathrm{CaO}$ dan $\mathrm{CaHO}_{2}$. Tujuan utama penggunaan kapur untuk stabilisasi tanah yaitu:

Kapur untuk memodifikasi sifat - sifat tanah, yaitu untuk mengurangi plastisitas, untuk menambah nilai CBR (California Bearing Ratio).

Stabilisasi tanah pada prinsipnya adalah untuk perbaikan mutu tanah yang kurang baik. Menurut Bowles (1991), cara untuk melakukan stabilisasi dapat terdiri dari salah satu tindakan sebagai berikut:

1. Menambah kerapatan tanah

2. Menambah material yang tidak aktif sehingga mempertinggi kohesi atau tahanan geser

3. Menambah material untuk menyebabkan perubahan - perubahan kimiawi

4. Mengganti tanah yang buruk

5. Menurunkan muka air tanah

\section{METODE}

Sebelum melakukan penelitian. Terlebih dahulu hendaknya dilakukan persiapan dan pemerikaan material dan alat yang akan digunakan dalam penelitian ini.

Tabel 2. Jenis Dan Sumber Material Yang Digunakan

\begin{tabular}{lccc}
\hline No & Material & Persentase (\%) & Sumber Material \\
\hline \multirow{2}{*}{1} & \multirow{2}{*}{ Tanah } & $94 \%$ & \multirow{2}{*}{ Quarry Bayung Lencir } \\
\cline { 3 - 3 } & & $93 \%$ & \multirow{2}{*}{ Toko Bangunan } \\
\cline { 3 - 3 } 2 & \multirow{2}{*}{ Kapur Tohor } & $92 \%$ & \\
\cline { 3 - 3 } & & $6 \%$ & $7 \%$ \\
\hline
\end{tabular}

Sumber : Penelitian 2019

\section{Pengujian Di Laboratorium}

Agar bisa mendapatkan ketelitian yang lebih baik dan akurat maka, diperlukan penelitian di laksanakan di Laboratorium, guna untuk mendapatkan data tentang jenis dan sifat pada tanah tersebut, yaitu :

1. Penentuan Kadar Air Tanah 
2. Pengujian Berat Jenis Tanah

3. Pengujian Batas Plastis Tanah

4. Penentuan Batas Cair Tanah

5. Plastis Index

6. Gradasi Butir Tanah

7. Pemadatan Standar (Standart Proctor)

8. Pengujian Uji CBR (California Bearing Ratio)

\section{HASIL DAN PEMBAHASAN}

\section{Karakteristik Tanah Lempung Ekspansif}

Tanah lempung Ekspansif dari Quarry Bayung Lencir, contoh tanah diambil dalam keadaan terganggu (disturbed), dengan bentuk bongkahan - bongkahan tanah,. Berdasarkan visual dan menggunakan buku Munsell Soil Color Chart 1994, menunjukkan bahwa tanah tersebut berwarna Coklat keabu - abuan. Sedangkan menurut pengujian di Laboratorium, hasilnya seperti pada tabel dibawah ini:

Tabel 3. Karakteristik Tanah

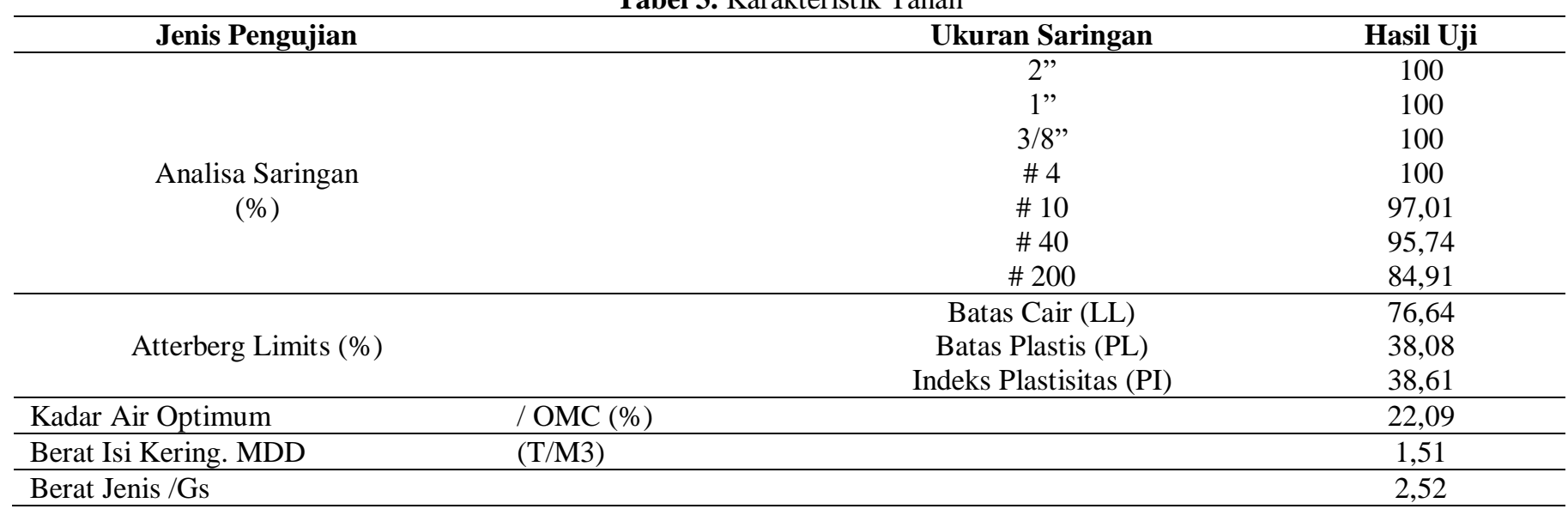

Sumber : Hasil Pengujian, 2020

Berdasarkan hasil pengujian di atas dapat dilihat bahwa nilai PI di dapat 38,61\% dan nilai LL 76,64 \% adalah termasuk tanah dengan pengembangan tinggi.

\section{Berat Jenis Campuran Tanah Dan Kapur Tohor}

Dari hasil pemeriksaan berat jenis tanah yang dicampur dengan kapur tohor dengan persentase $6 \% .7 \%$, dan $8 \%$ yang dilakukan di Laboratorium berdasarkan SNI 03 - 1964 - 2008. Hasil Pemeriksaan dirangkum dalam tabel dibawah ini:

Tabel 4. Hasil Pengujian Berat Jenis

\begin{tabular}{cc}
\hline Kode Sampel & Berat Jenis \\
\hline S0 & 2,52 \\
S6 & 2,53 \\
S7 & 2,54 \\
S8 & 2,55 \\
\hline
\end{tabular}

Sumber : Hasil Pengujian, 2020

\section{Batas - Batas Konsistensi (Atterberg Limits) Campuran Tanah Dan Kapur Tohor}

Hasil dari pengujian Atterberg Limits yang dicampur dengan kapur 0\%, 6\%, 7\%, dan 8\% yang dilakukan di Laboratorium berdasarkan SNI 1966 - 2008 dan SNI 1967 - 2008 dari berat kering tanah dengan pemeraman 1 x 24 jam.

Tabel 5. Batas Batas Atterberg Tanah Yang Distabilisasi Dengan Kapur

\begin{tabular}{cccc}
\hline Kode Sampel & Kadar Air Batas Cair (\%) & Kadar Air Batas Plastis (\%) & Indeks Plastisitas (\%) \\
\hline S0 & 76.64 & 38.03 & 38.61 \\
S6 & 70.57 & 37.47 & 33.10 \\
S7 & 60.05 & 35.53 & 24.52 \\
S8 & 38.30 & 20.33 & 17.97 \\
\hline
\end{tabular}




\section{Analisis Distribusi Butir Tanah Yang Distabilisasi Dengan Kapur Tohor}

Dari beberapa variasi perhitungan Analisa saringan yang dilakukan di Laboratorium maka didapat hasil rata rata lolos saringan antara lain :

Tabel 6. Hasil Analisis Dalam Uji Butir

\begin{tabular}{|c|c|c|c|c|c|c|c|c|}
\hline \multirow{3}{*}{ \# Saringan } & \multicolumn{2}{|c|}{$\begin{array}{l}\text { Tanah100\% } \\
+ \text { Kapur0\% }\end{array}$} & \multicolumn{2}{|c|}{$\begin{array}{l}\text { Tanah } 94 \% \\
+ \text { Kapur 6\% }\end{array}$} & \multicolumn{2}{|c|}{$\begin{array}{r}\text { Tanah } 93 \% \\
+ \text { Kapur 7\% } \\
\end{array}$} & \multicolumn{2}{|c|}{$\begin{array}{r}\text { Tanah } 92 \% \\
+ \text { Kapur } 8 \% \\
\end{array}$} \\
\hline & \multicolumn{2}{|c|}{ Kumulatif (\%) } & \multicolumn{2}{|c|}{ Kumulatif $(\%)$} & \multicolumn{2}{|c|}{ Kumulatif $(\%)$} & \multicolumn{2}{|c|}{ Kumulatif (\%) } \\
\hline & Tertahan & Lolos & Tertahan & Lolos & Tertahan & Lolos & Tertahan & Lolos \\
\hline No. 4 & 0.00 & 100 & 0.00 & 100 & 0.00 & 100 & 0.00 & 100 \\
\hline No. 10 & 7.51 & 97.01 & 9.66 & 90.34 & 8.82 & 91.18 & 8.51 & 91.49 \\
\hline No. 40 & 8.78 & 95.74 & 19.60 & 80.40 & 20.02 & 79.98 & 36.17 & 63.83 \\
\hline No. 200 & 19.61 & 84.91 & 33.70 & 66.30 & 37.35 & 62.65 & 45.53 & 54.47 \\
\hline
\end{tabular}

Sumber : Hasil Pengujian, 2020

Tabel 7. Jenis tanah berdasarkan klasifikasi AASHTO

Variasi Campuran Tanah dan Kapur Tohor $(\%)$

Tanah $100 \%+0 \%$ Kapur

Tanah $94 \%+6 \%$ Kapur

Tanah $93 \%+7 \%$ Kapur

Tanah $92 \%+8 \%$ Kapur

Sumber : Hasil Pengujian, 2020

\section{Kepadatan Standar Campuran Tanah Dan Kapur Tohor}

Dari hasil pengujian di Laboratorium yaitu pengujian kepadatan standar tanah yang dicampur dengan kapur 6\%, $7 \%$, dan 8\% menurut SNI - 1742 - 2008 untuk mendapatkan nilai kerapatan kering maksimal dan kadar air optimum (wopt) maka hasil pengujian dapat dirangkum pada tabel dibawah ini.

Tabel 8. Kepadatan Standar Proctor Campuran Tanah Dan Kapur

\begin{tabular}{ccc}
\hline Kode Sampel & Kadar Air Optimum $(\%)$ & Berat Isi Kering Maksimum $(\mathrm{\gamma d})\left(\mathrm{gr} / \mathrm{cm}^{3}\right.$ \\
\hline S0 & 23.16 & 1.51 \\
S6 & 24.47 & 1.50 \\
S7 & 26.92 & 1.45 \\
S8 & 27.18 & 1.42 \\
\hline
\end{tabular}

Sumber : Hasil Pengujian Di Laboratorium 2020

\section{CBR Laboratorium (California Bearing Ratio)}

Didapat nilai CBR Desain yang dapat dilihat pada tabel dibawah ini :

Tabel 9. Hasil Pengujian CBR Tanah $94 \%+6 \%$ Kapur Tohor

\begin{tabular}{lcccccc}
\hline \multicolumn{1}{c}{ Kode Sampel (S6) } & \multicolumn{3}{c}{ Langsung (hari) } & \multicolumn{3}{c}{ Rendaman (hari) } \\
\cline { 2 - 7 } & 0 & 3 & 24 & 0 & 3 & 24 \\
\hline Kadar Air Optimum ( \% ) & 23.22 & 23.22 & 23.22 & 23.22 & 23.22 & 23.22 \\
Densitas kering Maksimum ( $\square$ d maks) & 1.38 & 1.34 & 1.52 & 1.78 & 1.48 & 1.58 \\
Densitas Kering Desain ( 95 \% Maks ) & 1.31 & 1.27 & 1.44 & 1.69 & 1.41 & 1.50 \\
CBR Desain 95 \% MDD & 7.85 & 11.15 & 12.65 & 6.66 & 7.30 & 8.50 \\
CBR Desain 100 \% MDD & 11.96 & 13.66 & 14.81 & 7.69 & 10.25 & 11.52 \\
\hline
\end{tabular}

Sumber : Hasil Pengujian Di Laboratorium 2020

Tabel 10. Hasil Pengujian CBR Tanah $93 \%+7 \%$ Kapur Tohor

\begin{tabular}{|c|c|c|c|c|c|c|}
\hline \multirow{2}{*}{ Kode Sampel (S7) } & \multicolumn{3}{|c|}{ Langsung (hari) } & \multicolumn{3}{|c|}{ Rendaman (hari) } \\
\hline & 0 & 3 & 24 & 0 & 3 & 24 \\
\hline Kadar Air Optimum ( \% ) & 26.92 & 26.92 & 26.92 & 26.92 & 26.92 & 26.92 \\
\hline Densitas kering Maksimum ( $\square_{\mathrm{d}}$ maks $)$ & 1.36 & 0.00 & 1.30 & 1.48 & 1.52 & 1.44 \\
\hline Densitas Kering Desain ( $95 \%$ Maks ) & 1.29 & 0.00 & 1.24 & 1.41 & 1.44 & 1.37 \\
\hline CBR Desain $95 \%$ MDD & 11.45 & 0.00 & 21.40 & 7.65 & 10.90 & 17.40 \\
\hline CBR Desain $100 \%$ MDD & 17.93 & 0.00 & 41.97 & 14.30 & 20.07 & 28.81 \\
\hline
\end{tabular}

Sumber : Hasil Pengujian Di Laboratorium 2020 
Tabel 11. Hasil Pengujian CR Tanah $92 \%+8 \%$ Kapur Tohor

\begin{tabular}{lcccccc}
\hline \multicolumn{1}{c}{ Kode Sampel (S8) } & \multicolumn{3}{c}{ Langsung (hari) } & \multicolumn{3}{c}{ Rendaman (hari) } \\
\cline { 2 - 7 } & 0 & 3 & 24 & 0 & 3 & 24 \\
\hline Kadar Air Optimum ( \% ) & 27.18 & 27.18 & 27.18 & 27.18 & 27.18 & 1.48 \\
Densitas kering Maksimum $\left(\square_{\text {d }}\right.$ maks) & 1.40 & 1.47 & 1.30 & 1.47 & 1.52 \\
Densitas Kering Desain ( 95 \% Maks ) & 1.33 & 1.39 & 1.24 & 1.40 & 1.41 & 1.44 \\
CBR Desain 95 \% MDD & 13.80 & 17.60 & 33.50 & 7.70 & 14.30 & 27.95 \\
CBR Desain 100 \% MDD & 20.92 & 25.19 & 64.19 & 14.95 & 23.91 & 45.27 \\
\hline
\end{tabular}

Sumber : Hasil Pengujian Di Laboratorium 2020

Tabel 12. CBR Desain

\begin{tabular}{cccc}
\hline Kode Sampel & 0 Hari & 3 Hari & 24 Hari \\
\hline S6 & 6.66 & 7.10 & 8.50 \\
S7 & 7.65 & 10.90 & 17.40 \\
S8 & 7.70 & 14.30 & 27.95 \\
\hline
\end{tabular}

Sumber : Hasil Pengujian Di Laboratorium 2020

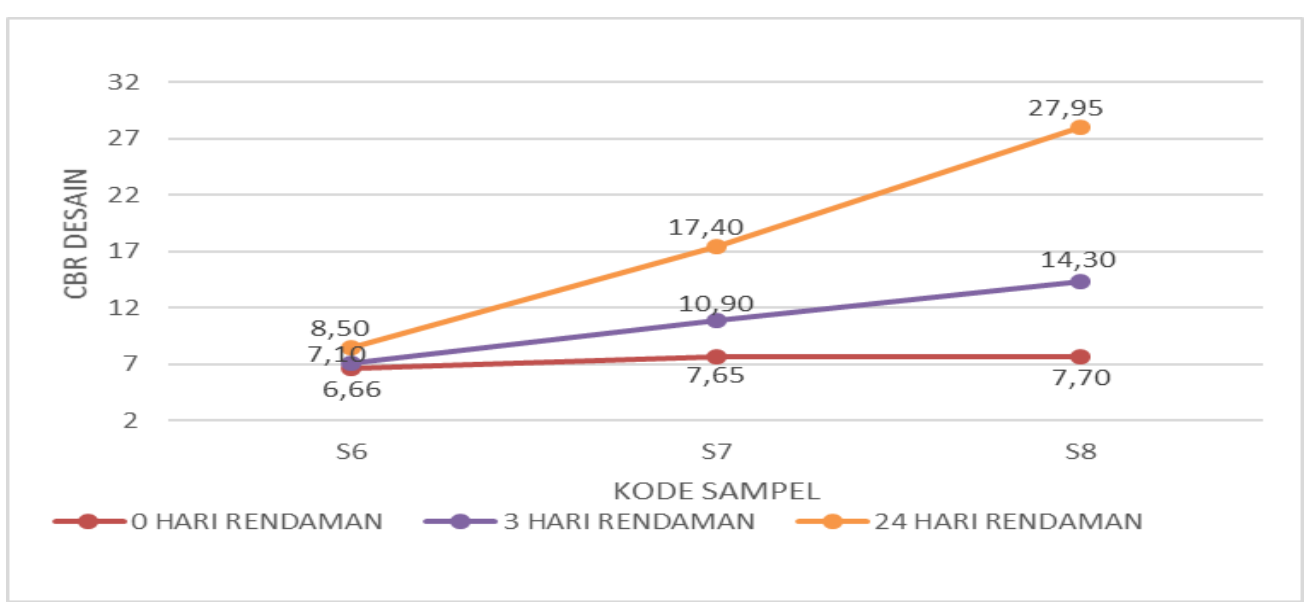

Sumber : Data Olahan 2020

Gambar 1. Grafik CBR Desain Sampel Uji Dengan Umur Pemeraman

\section{SIMPULAN}

Dari hasil penelitian di Laboratorium maka tanah dari Quarry Anggun Repsol Bayung Lencir adalah tanah lempung ekspansif dengan plastisitas tinggi PI $=38,61 \%$ dan $\mathrm{LL}=76,64 \%$ ). Menurut klasifikasi AASHTO tanah dari Quarry Anggun Repsol Bayung Lencir termasuk dalam golongan A - 7 - 5 yakni tanah sebagai bahan dasar yang jelek. Stabilisasi tanah dengan kapur tohor dihasilkan sebagai berikut :

1. Stabilisasi mengubah berat jenis tanah dari semula $0 \%$ ( S0 ) $=2,52,6 \%$ ( S6 ) $=2,53,7 \%$ ( S7 ) $=2,54$ menjadi $8 \%($ S8 $)=2,55$.

2. Penambahan kapur sebagai bahan stabilisasi menurunkan kadar air batas cair dari semula $76,64 \%$ ( S0 ), 70,57 \% ( S6 ), 60,05\% ( S7 ), dan 38,30\% ( S8 ).

3. Penambahan kapura tohor sebagai bahan stabilisasi menurunkan indeks plastisitas tanah dari semula 38,61\% ( S0 ), 33,10\% ( S6 ), 24,52 \% ( S7 ), dan 17,97\% ( S8 ).

4. Stabilisasi tanah dengan kapur tohor tersebut merubah jenis klasifikasi tanah, jenis klasifikasi tanah dapat dilihat pada tabel AASHTO untuk tanah $0 \%($ S0 $)=\mathrm{A}-7-5,6 \%$ ( S6 ) $=\mathrm{A}-7-5,7 \%(\mathrm{~S} 7)=\mathrm{A}-7-5,8 \%$ ( S8 ) $=\mathrm{A}-6$.

5. Stabilisasi tanah dengan kapur tohor $6 \%$ ( S6 ) meningkatkan nilai CBR desain dengan umur pemeraman 0 hari $=$ $6,66 \%$ dan meningkat menjadi 7,30\% setelah pemeraman 3 hari, dan menjadi 8,50\% setelah pemeraman 24 hari.

6. Stabilisasi tanah dengan kapur tohor $7 \%$ ( S7 ) meningkatkan nilai CBR desain dengan umur pemeraman 0 hari $=$ $7,65 \%$ dan meningkat menjadi $10,90 \%$ setelah pemeraman 3 hari, dan menjadi 17,40\% setelah pemeraman 24 hari.

7. Stabilisasi tanah dengan kapur tohor $8 \%$ ( S8 ) meningkatkan nilai CBR desain dengan umur pemeraman 0 hari $=$ $7,70 \%$ dan meningkat menjadi 14,30\% setelah pemeraman 3 hari, dan menjadi 27,95\% setelah pemeraman 24 hari.

8. Pada spesifikasi Bina Marga Devisi 3 syarat CBR untuk tanah timbunan pilihan adalah $10 \%$, jadi pada stabilisasi tanah dengan kapur tohor maka didapat CBR desain yang memenuhi syarat pada campuran $7 \%$ ( S7 ) yaitu pada umur pemeraman 3 hari dengan nilai CBR 10,90\%. 
Dari ketiga variasi campuran tanah dan kapur tohor tersebut maka didapat nilai CBR (California Bearing Ratio) desain yang memenuhi syarat yaitu pada campuran $7 \%$ ( S7 ) dengan nilai CBR 10,90\% pada umur pemeraman 3 hari, karena mengingat harga kapur tohor mahal maka hanya diambil nilai CBR yang memenuhi atau mendekati syarat minimal tanah timbunan pilihan.

\section{DAFTAR PUSTAKA}

Bowles, J.E.1991. Sifat - Sifat Fisik Tanah dan Geoteknik Tanah. Edisi ke II. Erlangga Jakarta.

Craig, R.F.1991. Mekanika Tanah. Edisi ke IV. Erlangga. Jakarta.

Das, Braja M.1995. Mekanika Tanah Jilid I. Erlangga. Jakarta.

Damawati, Fitri. 2017. Stabilisasi Tanah Dengan Variasi Penambahan Kapur Dan Waktu Pemeraman.

Hardiyatmo.1992, Mekanika Tanah I. Gajah Mada University. Yogyakarta.

Sudjianto Agus. 2015. Tanah Ekspansif. Graha Ilmu.

Situmorang, Bahtiar Efendi. 2018. Pengaruh Waktu Pemeraman Dengan Penambahan Kapur Sebagai Bahan Additive Pada Tanah Lepung Ekspansif Terhadap Nilai CBR Tanah.

Sudjianto, Agus Tugas. 2014. Tanah Lempung ekspansif. Graha Ilmu. Yogyakarta.

Standar Nasional Indonesia, 1744 : 2012 Cara Uji CBR (California Bearing Ratio). Badan Standardisasi Nasional.

Standar Nasional Indonesia, 1742 : 2008 Cara Uji Kepadatan Ringan Untuk Tanah. Badan Standardisasi Nasional. Jakarta.

Standar Nasional Indonesia, 3423 : 2008 Cara Uji Penentuan Analisa Ukuran Butir Tanah. Badan Standardisasi Nasional. Jakarta

Standar Nasional Indonesia, 1967 : 2008 Cara Uji Penentuan Batas Cair Tanah. Badan Standardisasi Nasional. Jakarta.

Standar Nasional Indonesia, 1966 : 2008 Cara Uji Penentuan Batas Cair Dan Indeks Plastis Tanah. Badan Standardisasi Nasional. Jakarta 